\title{
The RTU Graduate School Executive Master's Program for School Year 2011-2012 as Viewed by its Respondents
}

\author{
Leonila C. Crisostomo \\ Research and Development Center \& College of Business and Entrepreneurial Technology, Rizal \\ Technological University, Philippines \\ Email address: crisostomoleonila@yahoo.com
}

\begin{abstract}
Keywords: Executive Master's Program, Master of Arts in Education, Master of Arts in Engineering, Recipients
\end{abstract}

\begin{abstract}
This study was conducted to ascertain the views and opinions of the faculty and personnel as recipients of the Rizal Technological University (RTU) Graduate School Executive Master's program as to its reasons for availment, importance of the core and major subjects of the curriculum, lecturers' professional skills, duration/time allotment, level of satisfaction, significant difference of the two programs, problem encountered and gathered possible solutions to the problems; determine whether the Executive Master's Program was able to realize its goals and objectives and find out the overall impression of the recipients about the Executive Master's Program. A total of fifty (50) RTU faculty and personnel graduated from this Executive Master's program, twenty six (26) Master of Arts in Education (MAEd) and twenty four (24) Master of Arts in Engineering (MAE).
\end{abstract}

\section{INTRODUCTION}

It has been repeatedly said since time immemorial that the only thing constant in this world is change. Change is an enduring historical force with noticeable variations through time [2]. It may be hardly discernible or easily observable. It may be constructive. It occurs everywhere and every time. To encourage further the faculty to enroll in the graduate program the administration set the policy of free tuition fee for those who have rendered five (5) years of service on a permanent status of employment. Still may refused to enroll in the RTU Graduate School and so another policy was enforced that of, no faculty member would be given a part time load if he or she does not enroll GS courses. To comply with this policy, faculty members did enroll but some eventually dropped their GS subjects after that faculty teaching load was approved.

In 2011 Dr. Jesus RF Torres, then the Vice President for Academic Affairs, now the RTU President, conceptualized the offering of the Executive Master's program for RTU personnel who up until that year have not finished their Master's degrees. This is also part of RTU faculty and personnel development program to make them qualified as tertiary educators, internalize their moral obligation to grow professionally as a members of an academic community as change agents to students under their tutelage, and comply with CHED requirement.

Two programs were offered Masters of Arts in Education (MAEd) and Masters of Arts in Engineering (MAEng) both of which are non-thesis curricula. A specific curriculum for each was developed but very similar to existing MAEM and MSEE regular programs. There are core subjects and seven major ones for a total of 30 units at three units per subject. The programs were culminated by an action research/seminar paper presented to a committee of evaluators.

These two Master's program began in July 2011 and ended in March 2012. Most of the lecturers were sourced from other universities and agencies. The reason for this was perhaps to rule out favoritism and familiarity between them and the RTU faculty and personnel. A total of fifty (50), RTU personnel graduated from this Executive Master's program, twenty six (26) MAEd and twenty four (24) MAEng.

This research aims to ascertain the views and opinioins of the recipients of the program, specifically to (1) determine the recipients view of the Executive Master's Program, with regards to their reason for availment of the program, importance of the core and major subjects of the 
curriculum, lecturer's professional skills, and duration and time allotment, (2) to determine the level of satisfaction of the recipients of the program, (3) to determine the difference in the views/points of the MAEng and MAEd students, (4) to identify the problems encountered by the recipients in the course of the program, and (5) the recipients suggestions to remedy the perceived problems in the program.

\section{EDUCATIONAL CHANGE}

Change is everywhere and is taking place in culture, society and personality. Change in culture brings about change in society and human beings; likewise change in society and human being about changes in culture. It is a vicious cycle.

Changes refers to all alterations affecting human existence. This includes [2] 1) the development of oral and written language and other means of communication; 2) modification in technology; 3) shifts in economic principles; 4) the historical evolution of religious ritual and dogma, and educational philosophy and political ideology; 5) variations in musical styles and other art forms; 6) transition in scientific theories; and 7) alteration in the forms and rules in social interaction.

Technological change and social change are specific parts of culture change. Technological change brings about the revisions that occur in people's application of technological knowledge and skills as they adapt to their physical environment. These changed are manifested in 1) the increasing divergence in the forms of tools, instruments and implements used;2) the obsolescence and advancement in scientific knowledge; and 3) innovations in the ability to utilize and exploit natural environment for human needs [2].

I the present study, responding to change is underscoring the role of education because education is a process in which knowledge, skills, habits, values of a group of people are transferred from one generation to the next through teaching, training, research, or simply auto deduction. The purpose of this is to prepare the individual for effective participation in society and become a good citizen of the country.

The government has not been remiss in its duties to educate its citizenry to make them adaptable to the ever changing environment be it physical, social, cultural or technological.

A review of the provisions of the past and the present constitutions is a veritable proof of the government's effort to equip its citizenry with how to make them adaptable to these changes.

To enumerate those provisions

1. 1935 Philippine Constitution, Article XIX_Section 5. [6]

1.1 The government shall establish and maintain a complete and adequate system of public education, and shall provide at least free primary instruction and citizenship training to adult citizens. The state shall create scholarships in the Arts, Science and Letters for special gifted citizens.

2. 1973 Philippine Constitution Article XV [1]

All educational institutions shall aim to inculcate love of country, teach the duties of citizenship, and develop moral character, personal discipline and scientific, technological and vocational efficiency.

3. 1987 Philippine Constitution Article XIV [4]

All educational institutions shall inculcate patriotism and nationalism, foster love of humanity, respect for human rights, appreciation of the role of national heroes in the historical development of the country, teach the rights and duties of citizenships, strengthen ethical and spiritual values, develop moral character and personal discipline, encourage critical and creative thinking, broaden scientific and technological knowledge and promote vocational efficiency.

4. Educational Act of 1982 [5]

The educational system aims to:

4.1 Provide for broad general education that will assist each individual in the peculiar ecology in his own society, to (a) attain his potentials as human being; (b) enhance the range and quality of individual and group participation in the basic functions of 
society; and (c) acquire the essential educational foundation of his development into a productive and versatile citizen;

4.2 Train the nation's manpower in the mi9ddle-level skills required for national development.

4.3 Develops the professions that will provide leadership for the nation in the advancement of knowledge for improving the quality of human life, and

4.4 Respond effectively to changing needs and conditions of the nation through a system of educational planning evaluation.

The preceding Education Act of 1982 took into account the recommendations and findings of the Presidential Commission to Study Philippine Education which was created in 1969 [3] . PCSPE concluded that the Philippine educational system was not responding to the demands of the economy for national development.

4. EDCOM of 1991 [7] concluded that the quality of education was declining due to: 1) the government was not investing enough in the education system, and 2) the education department was poorly managed.

There were several recommendations forwarded by the EDCOM. Among others, it recommended for the government to ensure that the best and most qualified professionals become teachers and administrators.

This recommendation of EDCOM by providing these teachers with good tertiary education and with continuing education through in service training, attendance to seminars and conferences nationally and internationally and opportunities for them to pursue master's and doctoral degrees to continually equipped them with new knowledge, ideas, skills, values, norms and other things that need to be transmitted to learners enabling them to adjust/adapt and survive in a constantly changing world.

In the words of Dr. Nilo L. Rosas (2010) there is a never ending quest for quality teaching and in the heart of this quest to improve teaching is the teacher who might be said the pivotal factor in the teaching and learning process. He also adds that the teacher is the greatest player and decision-maker in the arena where learning takes place and, given a good teacher, learning can be made to happen despite deficiencies in the curriculum, technologically-deprived classrooms, and inadequacy of instructional materials and even with unmotivated learners. The good teacher will be able to transform these obstacles to opportunities.

The Rizal Technological University in its desire to comply with CHED requirements has continuously implemented its faculty development program most especially in giving opportunities to its faculty members to pursue not only Master's degree but also doctoral ones not only in RTU but also in other universities here and abroad.

For those who opted to pursue graduate studies in RTU, free tuition fee was very enticing not to mention travel time saved in the process.

However, the number of graduates still left so much to be desired. The RTU administration wanted to know the reasons for the inability of the RTU faculty graduate students to finish their programs. In 2002, therefore, Dr. Rogelio T. Viaña the then Vice President for Research and Extension Services and Dr. Amelita L. De Guzman, the then Dean of the Graduate School were commissioned to study the offerings of alternative Master's Program for the RTU Personnel. Conclusions were mentioned previously in chapter 1 , and in the light of the findings and conclusions, the commissioned researchers did not recommend the offering of non-thesis programs by the RTU Graduate School on the following grounds:

1. The reason for the failure of RTU Personnel to finish their Master's degrees lies not on their inability to write thesis but on the constraints that they encounter in undertaking advanced studies.

2. The students should measure up with the high standards of the RTU Graduate School rather than water them down to suit the purposes of the students. Thesis writing and comprehensive examination examinations are effective ways of enhancing the quality of graduates of the RTU Graduate School. 
3. The University cannot offer a graduate course exclusively for RTU personnel because it is violative of the equal protection of laws and equal opportunity clause of the Bill of Rights of the Constitution.

Instead, the sub-committee recommended the implementation of the following courses of action.

1. Implement the "Adopt-a-Graduate Student Program" wherein a faculty who has earned his/her PhD will mentor a fellow faculty member in thesis writing. The mentor would earn points for his/her services for purposes of NBC-461 and for ranking (promotion).

2. Conduct a study on the constraints encountered by the RTU personnel in undertaking their advanced studies. Findings to be elicited from such research will be the bases for implementing intervention measures.

3. Make at least the passing of the comprehensive examinations a precondition for a permanent appointment of newly hired faculty.

4. The GSSA should take the initiative to request and organize review classes for comprehensive examinations particularly on its statistics component.

5. The CEIT faculty should be encouraged to enroll in the MSEE program by giving bigger weight to an MS than an MA vis-à-vis promotion, and by implementing the policy on MSEE team research.

6. Strengthen the practice which requires the Master's students in Methods of Research to come up with quality thesis proposal which can be treated as their theses proper.

7. Make official and sustain the implementation of the policy which makes enrolment in the graduate school a precondition for availing of the part-time teaching load privilege.

8. Provide incentives of earning advanced degrees - e.g. giving bigger weight to and/or prioritizing those with advanced studies in ranking candidates for promotion.

9. Make the faculty internalize their moral obligation to grow professionally as members of an academic community through seminars and meetings, and making the same obligation a part of the Faculty Handbook or Faculty Code of Professional Ethics which could be adopted to include other professional obligations of faculty.

10. Establish day-care centers to cater to the parenting needs of faculty with small children.

11. In addition to Language Instruction as a major in Master of Arts in English, offer Filipino Instruction as another specialization in MAE. This is to help those who dread defending their theses in English.

Contrary to one of the recommendations of the sub-committee, the Administration offered a non-thesis GS program, Master of Arts in Teaching, Major in Educational Management in 2003 to address the problem of faculty's inability to finish their graduate courses.

In 2008, the then Dean of the Graduate School, Dr. Ruth S. Guzman, implemented an amnesty policy for GS students who have exceeded the number of maximum years to complete their MA/MS and doctoral degrees by not enrolling anymore in refresher courses. The amnesty gave the students only a year to comply. However, a little extension was granted to some students who were unable to finish their graduate programs within the prescriptive period.

This amnesty enabled 62 students to graduate under the regular thesis program and 12 nonthesis or MAT-EM. It is sad to note though that one (1) candidate from the MAT-EM curriculum was not able to comply with the amnesty policy of the Graduate School for SY $2008-2009$.

Another effort exerted by the RTU administration to respond to the educational needs to not only to its faculty but also other teachers from other schools, was the offering of Master of Arts in Science (MASE) which science faculty can pursue instead of enrolling in courses that are not aligned with their field of specialization. This is also veritable path towards vertical articulation which the CHED has been promoting in both SUC's and private institutions. 


\section{THE RECIPIENTS VIEW OF THE EXECUTIVE MASTER'S PROGRAM}

Table 1. Frequency, Percentage and Rank Distributions of the Reasons for Availment of the Executive Master's Program

\begin{tabular}{|l|c|c|c|}
\hline Reasons for Availment of the EMP & Frequency & Percentage & Rank \\
\hline 1. Knowledge for its own sake & 2 & 4.00 & 5 \\
\hline 2. Professional growth and development & 24 & 48.00 & 1 \\
\hline 3. Promotion & 14 & 28.00 & 2 \\
\hline 4. Requirements for part-time load & 4 & 8.00 & 4 \\
\hline 5. CHED Requirements & 6 & 12.00 & 3 \\
\hline \multicolumn{1}{|c|}{ Total } & 50 & 100.00 & \\
\hline
\end{tabular}

It can be gleaned from Table 1 that majority of the respondents availed of the Executive Master's Program for professional Growth and Development with a frequency of 24 or 48\%, ranked 1. Fourteen or $28 \%$ say it's for Promotion, ranked 2 while 6 or $12 \%$ state for HCED requirement, ranked 3.

It is observed that those who availed this Executive Master's program are for them, as used by Maslow, the realization of potentials or engagement in activities that the persons find directly fulfilling. The respondents focus on professional goals which increase the probability of success in their professions as faculty and personnel of the University at the same time comply with the requirements of CHED that faculty member in the tertiary education must be at least master degree holder.

\section{LEVEL OF SATISFACTION OF THE RECIPIENTS WITH THE EXECUTIVE MASTER'S PROGRAM}

Table 2 shows the distribution of responses as to level of satisfaction.

Table 2. Frequency and Percentage Distributions on the Level of Satisfaction to the Executive Master's Program

\begin{tabular}{|l|c|c|c|c|}
\hline \multirow{2}{*}{ Level of Satisfaction } & \multicolumn{2}{|c|}{ MAEng N=24 } & \multicolumn{2}{c|}{ MAEd N = 26 } \\
\cline { 2 - 5 } & Frequency & Percentage & Frequency & Percentage \\
\hline 5 - Very Satisfied & 16 & 66.67 & 21 & 80.77 \\
\hline 4- Satisfied & 8 & 33.33 & 5 & 19.23 \\
\hline 3 - Fairly Satisfied & 0 & & 0 & \\
\hline 2- Unsatisfied & 0 & & 0 & \\
\hline 1 - Very Unsatisfied & 0 & 100.00 & 0 & 100.00 \\
\hline
\end{tabular}

Table 2 presents that out of the 24 MAEng students, 16 or $66.67 \%$ were very satisfied with the Executive Master's Program. On the other hand, out of 26 MAED students, 21 or $80.77 \%$ were very satisfied. As a whole, out of 50 students, 37 or $74 \%$ were very satisfied while 13 or $26 \%$ were satisfied only with the program. It means that three fourth of the total number of students have very satisfaction level.

From the results of the survey, it is safe to say that the Executive Master's Program be again offered to address the needs of RTU faculty and personnel at the same time comply with CHED's requirements. 


\section{SIGNIFICANT DIFFERENCE IN THE VIEWS/OPINIONS OF THE MAENG AND MAED PROGRAM RECIPIENTS.}

\subsection{Reasons for Availment of the EMP}

Table 3. Difference in the Views and Opinions of EMP Recipients

\begin{tabular}{|l|r|r|c|c|c|}
\hline \multirow{2}{*}{$\begin{array}{c}\text { Two } \\
\text { Groups }\end{array}$} & \multicolumn{1}{|c|}{$\begin{array}{c}\text { Weighted } \\
\text { Mean }\end{array}$} & $\begin{array}{c}\text { Standard } \\
\text { Deviation }\end{array}$ & \multicolumn{2}{|c|}{ Z Score } & Interpretation \\
& & & Computed & Tabular & \\
\hline MAEd & 5.2 & 1.48 & & & No Significant \\
MSEE & 4.8 & 3.58 & 12.72 & 1.645 & Difference \\
\hline
\end{tabular}

The data on the views/opinions of the MAEd and MAEng students on reasons for availment which resulted to the computed Z-score 12.72 in which the value is found to be much higher than its tabular value at 1.645, showed that there is significant difference and, therefore, has failed to reject the null hypothesis. The MAEd and MAEng students have almost the same views on the lecturers' professional skills. This means that all the respondents found the lecturers very competent and knowledgeable in the subjects they handled.

The difference in the views/opinions of the MAEd and MAEng program recipients is attributed to other difference in the importance of the core and major subjects. The MAEd recipients viewed that all the subjects in their curriculum were consistently rated as very much important. On the other hand, the MAEng recipients rated two of the core subjects as more important only and two of the major subjects were equally rated as more important. Perhaps, their educational background in the field of engineering had already exposed them to the topics discussed in the subjects to render them one level lower than the other subjects of which they had less exposure like, for example, advanced instructional strategies or educational evaluation. The novelty of a subject makes it very interesting and very applicable to their duties and responsibilities.

5.2 Significant difference in the views/opinions of the MAEd and MAEng recipients on the lecturers' professional skills

Table 4. Z Scores on the Lecturers' Professional Skills

\begin{tabular}{|c|c|c|c|c|c|}
\hline \multirow{2}{*}{$\begin{array}{c}\text { Two } \\
\text { Groups }\end{array}$} & \multirow{2}{*}{$\begin{array}{l}\text { Weighted } \\
\text { Mean }\end{array}$} & \multirow{2}{*}{$\begin{array}{l}\text { Standard } \\
\text { Deviation }\end{array}$} & \multicolumn{2}{|c|}{ Z Score } & \multirow[t]{2}{*}{ Interpretation } \\
\hline & & & Computed & Tabular & \\
\hline MAEd & 4.88 & 0.023 & & & No Significant \\
\hline MSEE & 4.89 & 0.026 & 1389.31 & 1.645 & Difference \\
\hline
\end{tabular}

The data on the views/opinions of the MAEd and MAEng recipient's lecturers' professional skills which resulted to the computed z-score of 1389.31 in which value is found to be higher than its critical z-score of 1.645 showed that there is no difference, and, therefore, has failed to reject the null hypothesis. The MAEd and MAEng students have almost the same views on the lecturers' professional skills. This means that all the respondents found the lecturers very competent and knowledgeable in the subjects they handled.

5.3 Significant difference in the views/opinions of the MAEd and MAEng students on the level of satisfaction.

Table 5. Z Score on Level of Satisfaction of the Respondents

\begin{tabular}{|l|r|r|c|c|c|}
\hline \multirow{2}{*}{$\begin{array}{c}\text { Two } \\
\text { Groups }\end{array}$} & \multirow{2}{*}{$\begin{array}{c}\text { Weighted } \\
\text { Mean }\end{array}$} & $\begin{array}{c}\text { Standard } \\
\text { Deviation }\end{array}$ & \multicolumn{2}{|c|}{ Z Score } & Interpretation \\
\hline MAEd & 5.2 & 3.63 & & & \\
\hline MSEE & 4.8 & 2.98 & 10.66 & 1.645 & $\begin{array}{c}\text { Significant } \\
\text { Difference }\end{array}$ \\
\hline
\end{tabular}


The data on the views/opinions of the MAEd and MAEng students on the level of satisfaction which resulted to the computed z-score of 10.66 in which the value is found to be higher than its tabular z-score of 1.645 showed that there is significant difference, thus the failure to reject the null hypothesis. The MAEd students show higher level of satisfaction from the MAEng students.

5.4 Significant difference in the views/opinions of the MAEd and MAEng students on the importance of core and major subjects

Table 6. Z score on Importance of the Core and Major Subjects

\begin{tabular}{|c|c|c|c|c|c|}
\hline \multirow{2}{*}{$\begin{array}{c}\text { Two } \\
\text { Groups }\end{array}$} & \multirow{2}{*}{$\begin{array}{l}\text { Weighted } \\
\text { Mean }\end{array}$} & \multirow{2}{*}{$\begin{array}{l}\text { Standard } \\
\text { Deviation }\end{array}$} & \multicolumn{2}{|c|}{ Z Score } & \multirow[t]{2}{*}{ Interpretation } \\
\hline & & & Computed & Tabular & \\
\hline MAEd & 4.88 & 8.79 & & & Significant \\
\hline MSEE & 4.58 & 8.56 & 3.85 & 1.645 & Difference \\
\hline
\end{tabular}

The results on the views/opinions of the MAEd and MAEng students on the importance of core and major subjects obtained as to the computed z-score of 3.85 in which the value is higher than the tabular value of 1.645, likewise failed to reject the null hypothesis. The MAEd students state that all the core and major subjects are very much important to their profession than the MAEng students. This is because of the pre-service training of the MAEd recipients where the recipients study more education subjects as needed, while the MAEng recipients considered some of the subjects as repetition of what they had previously enrolled in.

5.5 Significant difference on the views/opinions of the MAEd and MAEng students on duration/time allotment.

Table 7. Z-score on Duration/Time Allotment

\begin{tabular}{|c|c|c|c|c|c|}
\hline \multirow{2}{*}{$\begin{array}{c}\text { Two } \\
\text { Groups }\end{array}$} & \multirow{2}{*}{$\begin{array}{l}\text { Weighted } \\
\text { Mean }\end{array}$} & \multirow{2}{*}{$\begin{array}{l}\text { Standard } \\
\text { Deviation }\end{array}$} & \multicolumn{2}{|c|}{ Z Score } & \multirow[t]{2}{*}{ Interpretation } \\
\hline & & & Computed & Tabular & \\
\hline MAEd & 4.83 & 0.0114 & \multirow[b]{2}{*}{3438.47} & \multirow[b]{2}{*}{1.645} & \multirow{2}{*}{$\begin{array}{l}\text { Very Significant } \\
\text { Difference }\end{array}$} \\
\hline MSEE & 4.24 & 0.0068 & & & \\
\hline
\end{tabular}

The obtained results on the views/opinions of the MAEd and MAEng students' duration/time allotment similarly got the computed z-score of 3438.47, in which the value is very much higher than the tabular value of 1.645 , likewise failed to reject the null hypothesis, that there is no significant difference. Therefore, there is very significant difference in the duration and time allotment. The MAEd students find the time allotment as very feasible than the MAEng which for them is only feasible. This shows that the students have good time management in the conduct of their study habits and on the whole, contented with the time allotted for the subject as well as the professorial lecturers finding time to answer queries.

\section{PROBLEMS ENCOUNTERED BY THE STUDENTS OF THE EXECUTIVE MASTER'S PROGRAM}

Table 8. Problems Encountered by the Recipients of the Executive Master's Program

$$
\text { MAEd } \mathrm{N}=26
$$

1. Limited Course Topic

2. Master's Program not in line with the Bachelor's Degree

3. Subjects are difficult

4. Inadequate interpersonal relationship

5. Lecturers are sometimes inaccessible for consultation 
6. Limited provisions for individual differences

7. Some lecturers fall short of expectation

$$
\text { MAEng } \quad \mathrm{N}=24
$$

1. Lecturers are sometimes inaccessible for consultation

2. Master's Program not in line with the Bachelor's degree

3. Limited Provisions for individual differences

4. Some lectures fall short of expectation

5. Limited course topics

6. Subjects are difficult

7. Inadequate interpersonal relationships

The MAEd students find the limited course topic as the most problem encountered followed by the Master's Program not in line with the Bachelor's Degree and subjects are difficult.

The MAEng students say that the lecturers are sometimes inaccessible for consultation followed by the Masters Program not in line with the Bachelors degree and limited provisions for individual differences.

It shows that the MAEd students hunger for more topics to be included through the topics offered are difficult while the MAEng students need more consultation hours with the lecturers and that the Master's Program are not in line with their Bachelor's Degree. It further presents that the MAEng have many more questions to ask to the lecturers however, the availability of time is not enough.

\section{SUGGESTIONS TO THE PROBLEMS ENCOUNTERED ON THE EXECUTIVE MASTER'S PROGRAM}

Table 9. Suggestions to the Problems Encountered on the Executive Master's Program

\begin{tabular}{|l|c|}
\hline \multicolumn{1}{|c|}{ Suggestions to the Problem Encountered } & Rank \\
\hline $\begin{array}{l}\text { 1. Longer time for each subject thus longer period for the whole program } \\
\text { requirements }\end{array}$ & 2 \\
$\begin{array}{l}\text { 3. More adequate assistance by the lecturers in terms of personal and vocational } \\
\text { guidance needed by the students. }\end{array}$ & 3 \\
$\begin{array}{l}\text { 4. More adequate materials and equipment in Management Information System } \\
\text { (MIS). }\end{array}$ & 4 \\
\hline
\end{tabular}

Table 9 depicts the suggestions to the problems encountered by the recipients of the Executive Master's Program. Since time allotted for each subject, is ranked no. 1, the students find the period spent for each subject not enough to learn more concepts and theories. The time perspective is an important consideration in assessing the possibility of the new program or its continuity. This is a specific need of concern and should be looked into whether the need is real or significant. Another suggestion is the consultation period in which the recipients asked for longer periods to help them monitor their progress, ranked 2. Also they expect assistance in mapping out other problems in areas of great academic strengths and enjoy a quality of work life in the graduate school. Since the MIS is a core subject, the students suggest more opportunities and extensive use of the MIS ranked 4.

The recipients are professional educators who show mental health perspectives ready to respond to the challenges of today's educational program. 


\section{CONCLUSION}

Based on the results and findings, the GS Executive Master's Program recipients avail of the program for professional growth and development. The core and major subjects are very important to the two programs. The recipients are very satisfied with the lecturers' professional skills. The duration/time allotment is feasible to MAEng and very feasible to MAEd. The MAEd and MAEng students differ on their views/opinions as to the EMP. The recipients are very satisfied with the EMP.

The problems encountered by MAEd recipients are limited course topic and limited access to the lecturers for consultation.The solutions suggested are longer time for each subject and longer consultation period with the lecturers.

Moreover, recommendations are stated that the administration may provide a continuous Executive Master's Program for the development of professional growth of the faculty members. The GS may extend the number of hours for each subject to learn more concepts and theories. The lecturers may give longer consultation periods to the recipients to monitor their progress. There may be guidance in academic and vocational counseling needed by students to be provided by the lecturers and the guidance counselors under the GS office.The Management Information System may need to upgrade the materials and equipment for the use of the GS students.The administration may look into a stricter implementation of the Master's degree qualification to teach in college and other CHED requirements. The university officials may review the policies on vertical articulation so that professional lecturers teach their fields of specialization. Likewise, vertical articulation be given importance to future recipients of EMP. The HR office may look into the needs of the faculty members to acquire Master's degree in other colleges and universities to have a different school cultural orientation to be introduced to RTU. The Administration may seek other means of recruitment from different colleges and universities in the country to minimize in-breeding practice. There may be related researches to be done by other researchers to validate the findings of this study.

\section{References}

[1] Bernas, J. (1974). The 1973 Philippine Constitution. Rex Bookstore. Manila

[2] David, K. (1949). Herman Society. The McMillan Publishing Co.

[3] Panopio, I. (2004). Sociology Focus on the Philippines. Ken Incorporated. Quezon City

[4] Sison, C. (2005). The 1987 Philippine Constitution. C\&E Publishing, Inc. Quezon City

[5] Information on http://www.gov.ph

[6] Information on http://www.gov.ph/constitutions/the-1935-consitution

[7] Information on http://www.senate.gov.ph 